\title{
De epidemiologie van kinderdoding in Nederland, 2009-2014
}

\author{
Marieke Liem \& Stephanie Haarhuis
}

Kinderdoding is een fenomeen dat niet zelden voor ontsteltenis en maatschappelijke onrust zorgt. De precieze aard en omvang van kinderdoding in Nederland zijn echter onbekend. Dit artikel poogt deze lacune te vullen door een beschrijvend verslag te doen van kinderdoding in Nederland gedurende de periode 2009-2014. Tevens wordt onderzocht of er mogelijk sprake is van een imitatie-effect door veelvuldige mediarapportage over kinderdoding. Door middel van beschrijvende statistieken worden resultaten weergegeven met betrekking tot zaak-, slachtoffer-en daderkarakteristieken van 74 kinderdodingszaken.

\section{$1 \quad$ Inleiding}

Het fenomeen kinderdoding bestaat sinds mensenheugenis. Kinderdodingen worden in de literatuur op verschillende manieren gedefinieerd. Neonaticide verwijst naar het doden van een kind binnen 24 uur na de geboorte. Infanticide betreft het doden van een kind ouder dan één dag en jonger dan één jaar. De term filicide behelst het doden van een kind ouder dan één jaar. Filicide wordt tevens vaak gebruikt als een verzamelnaam voor kinderdodingen gepleegd door de vader of moeder (Brants \& Koenraadt 1998; Koenraadt \& Liem 2007).

Bij de bestudering van kinderdoding dient een belangrijk onderscheid te worden gemaakt tussen intra-familiale kinderdodingen, waarbij een kind door een familielid of verzorger wordt gedood, en extra-familiale kinderdodingen, waarbij een kind door een buitenstaander wordt gedood. Waar bij de laatstgenoemde categorie vaak wordt gehandeld vanuit een seksueel motief, is hiervan zelden sprake bij intra-familiale kinderdodingen (Koenraadt 2003; Koenraadt \& Liem 2007). Gezien de relatief lage incidentie van extra-familiale kinderdodingen en de grote verschillen tussen beide typen kinderdodingen, richten we ons in dit onderzoek op intra-familiale kinderdodingen. Wanneer het in dit onderzoek over ouders gaat, worden naast biologische en stiefouders tevens adoptie- en pleegouders bedoeld.

Eerder onderzoek naar fataal geweld in Nederland wijst uit dat er in de periode 1992-2006 in totaal 134 slachtoffers van kinderdodingen zijn gevallen, wat neerkomt op acht à negen kinderdodingen per jaar (Van Os, Nieuwbeerta \& Ganpat 2010). Van alle levensdelicten in Nederland is het aandeel kinderdodingen jaarlijks ongeveer $4 \%$. Volgens grootschalig internationaal onderzoek naar trends in infanticide, waarbij gebruik is gemaakt van sterftecijfers van de WHO, kent Nederland voor de periode 1960-2009 een ietwat opwaartse trend (Ellonen, Kääriäinen, Lehti \& Aaltonen 2015). Tot op heden ontbreekt het in Nederland echter 
aan een gedetailleerd epidemiologisch overzicht van de aard en incidentie van kinderdoding. Daarnaast is onduidelijk hoe kinderdoding zich de laatste jaren in Nederland heeft ontwikkeld. Bovendien is er sprake van een dark number bij kinderdodingen. Het is immers mogelijk dat vrouwen zwanger zijn zonder medeweten van anderen en dat deze vrouwen na de bevalling hun baby doden en verbergen (Adinkrah 2001; Resnick 1970; Yasumi \& Kageyama 2009).

Dit onderzoek tracht een overzicht te geven van de aard en omvang van kinderdoding in Nederland voor de periode 2009-2014. Hiertoe bestuderen we de karakteristieken van zaken, slachtoffers en daders. Pogingen tot moord of doodslag worden niet meegenomen. Onopgeloste zaken en zaken waarbij de dader niet is vervolgd, bijvoorbeeld bij kinderdoding gevolgd door zelfdoding van de dader, zijn wel meegenomen in dit onderzoek. Dit onderzoek richt zich op zaken waarin voltooide (kinder)moord of (kinder)doodslag ten laste is gelegd. In het Nederlandse strafrecht zijn kindermoord (art. 291 Wetboek van Strafrecht; hierna: WvS) en kinderdoodslag (artikel $290 \mathrm{WvS}$ ) zogenoemde 'geprivilegieerd delicten', dat wil zeggen delicten waarop een strafverminderende omstandigheid van kracht is. Het gaat hierbij om een delict dat alleen door de moeder is gepleegd kort na de geboorte, onder de vrees voor ontdekking van de bevalling. De strafmaat is maximaal negen jaar gevangenisstraf bij kindermoord en zes jaar bij kinderdoodslag. Voor vaders die een dergelijk delict plegen, geldt een dergelijke vermindering niet (Koenraadt 2003).

Daarnaast wordt in dit onderzoek gekeken of er mogelijk een copycat-effect bestaat bij kinderdoding in Nederland. Aangezien kinderdoding vaak uitgebreid wordt gerapporteerd in de media, zou dit tot imitatiegedrag kunnen leiden (Brants \& Koenraadt 1998). Zo werd in 1997 in navolging van een aantal kinderdodingen gepleit voor zes maanden mediastilte rondom kinderdoding (Wijfjes 1997). Het is tot nu toe onbekend in hoeverre de aard en incidentie van kinderdoding is toe te schrijven aan een mogelijk copycat-effect.

\section{Eerder onderzoek}

\subsection{Classificaties van kinderdoding}

Kinderdoding wordt in de literatuur op diverse manieren geclassificeerd. Zo hebben de Canadese onderzoekers Bourget en Bradford (1990) een classificatiesysteem opgezet aan de hand van motieven. Hierin onderscheiden zij ten eerste de categorie pathologische filicide, verwijzende naar dodingen die gepleegd worden vanuit een ernstige psychische stoornis. Subcategorieën hiervan vormen de verlengde zelfdoding, ook wel extended suicide, waarbij het kind gedood wordt vlak voordat de dader zelfdoding pleegt of een poging daartoe doet. De extended suicide is niet zelden gekoppeld aan een symbiotische band tussen dader en slachtoffer (Liem \& Koenraadt 2007). Een tweede subcategorie vormt de altruïstische doding, ofwel mercy killing (Bourget \& Bradford 1990; Porter \& Gavin 2010), waarbij de dader het kind doodt om het kind uit een (vermeend) lijden te verlossen of te beschermen tegen echt dan wel ingebeeld onheil (Liem \& Koenraadt 2008a; Resnick 1969). Onder daders van deze twee subcategorieën komen psy- 
chotische stoornissen, depressieve stoornissen en eerdere suïcidaliteit veelvuldig voor (Liem \& Koenraadt 2008a).

De tweede categorie, tevens de grootste in omvang (Nielssen, Large, Westmore \& Lackersteen 2009; Sidebotham, Bailey, Belderson \& Brandon 2011; Yasumi \& Kageyama 2009), betreft kinderdoding als ongeluk, bijvoorbeeld voortvloeiende uit een ernstige mishandeling waarbij de dood een onbedoeld gevolg is. Hieronder valt tevens het battered child syndrome (Bourget \& Bradford 1990).

De derde categorie bestaat uit het doden van een kind uit wraak tegen de (ex-)partner, met als doel de (ex-)partner te laten lijden (Rougé-Maillart, Jousset, Gaudin, Bouju \& Penneau 2005; Bourget e.a. 2007; Resnick 1969) en staat ook wel bekend als het Medea-complex (Stern 1948; Bourget e.a. 1990), vernoemd naar de Griekse mythe van Medea en Jason. Zij kregen twee zoons, die door Medea uit wraak werden gedood toen Jason haar verliet voor een andere vrouw. Het zijn echter niet alleen vrouwen die hun kinderen doden vanuit wraakgevoelens tegenover (ex-)partners; in tegenstelling tot enkele eeuwen geleden zijn mannen tegenwoordig de voornaamste daders van dit type dodingen (Lewis \& Bunce 2003; Liem \& Koenraadt 2008a).

Neonaticide betreft de laatste categorie: het doden van een kind in de eerste dag na de geboorte. Hieronder wordt tevens het doden van een ongewenst kind geschaard, alsook verwaarlozing van een kind (Brants \& Koenraadt 1998; Resnick 1969).

Naast classificaties op basis van het motief van de dader en leeftijd van het slachtoffer worden kinderdodingen ook geclassificeerd naar type slachtoffers: zo wordt er gesproken van familicide als naast kinderen ook (ex-)partners gedood worden (Wilson, Daly \& Daniele 1995). ${ }^{1}$ Wanneer kinderdoding gevolgd wordt door zelfdoding van de dader, spreekt men in de literatuur over filicide-suïcide. Wanneer het een onvoltooide zelfdoding betreft, wordt dit filicide-parasuïcide genoemd (Liem, De Vet \& Koenraadt 2010).

\section{Zaak-, slachtoffer- en daderkarakteristieken van kinderdoding}

\subsection{Zaakkarakteristieken}

Tabel 1 geeft een overzicht van eerdere studies naar kinderdoding. Onderzoek van Baralic (2010) wijst uit dat de meeste kinderdodingen binnenshuis plaatsvinden, wat kan worden toegeschreven aan de familieband tussen dader en slachtoffer. Tevens wijst eerder onderzoek uit dat vaders en moeders verschillende modus operandi gebruiken. Vaders gebruiken eerder schietwapens en bij moeders komt vergiftiging, verwaarlozing en verdrinking eerder voor (Koenraadt \& Liem 2007; Putkonen, Amon, Eronen, Klier, Almiron, Yourstone-Cederwall e.a. 2010). Ook blijkt dat biologische ouders vaak snelle, 'pijnloze' methoden verkiezen, terwijl stiefouders vaker gewelddadige methoden zoals verwurging, vuurwapens of fysieke mishandeling gebruiken (Daly \& Wilson 1994; Weekes-Shackelford \&

1 De familicide, waarbij de dader zijn ouder(s) en broers/zussen ombrengt, blijft hier buiten beschouwing. 
Shackelford 2004). Volgens onderzoek van Putkonen e.a. (2010) en Bourget e.a. (2007) blijkt dat vaders vaker dan moeders zelfdoding plegen na kinderdoding en dat vaders vaker een drugs- of drankverslaving hebben. Eerder Nederlands onderzoek heeft uitgewezen dat kinderdoding een zogenoemd 'geëmancipeerd delict' is; dit geldt voor zowel slachtoffers als daders. Dit houdt in dat de verdeling tussen mannen en vrouwen ongeveer gelijk is (Koenraadt $\&$ Liem 2007). 


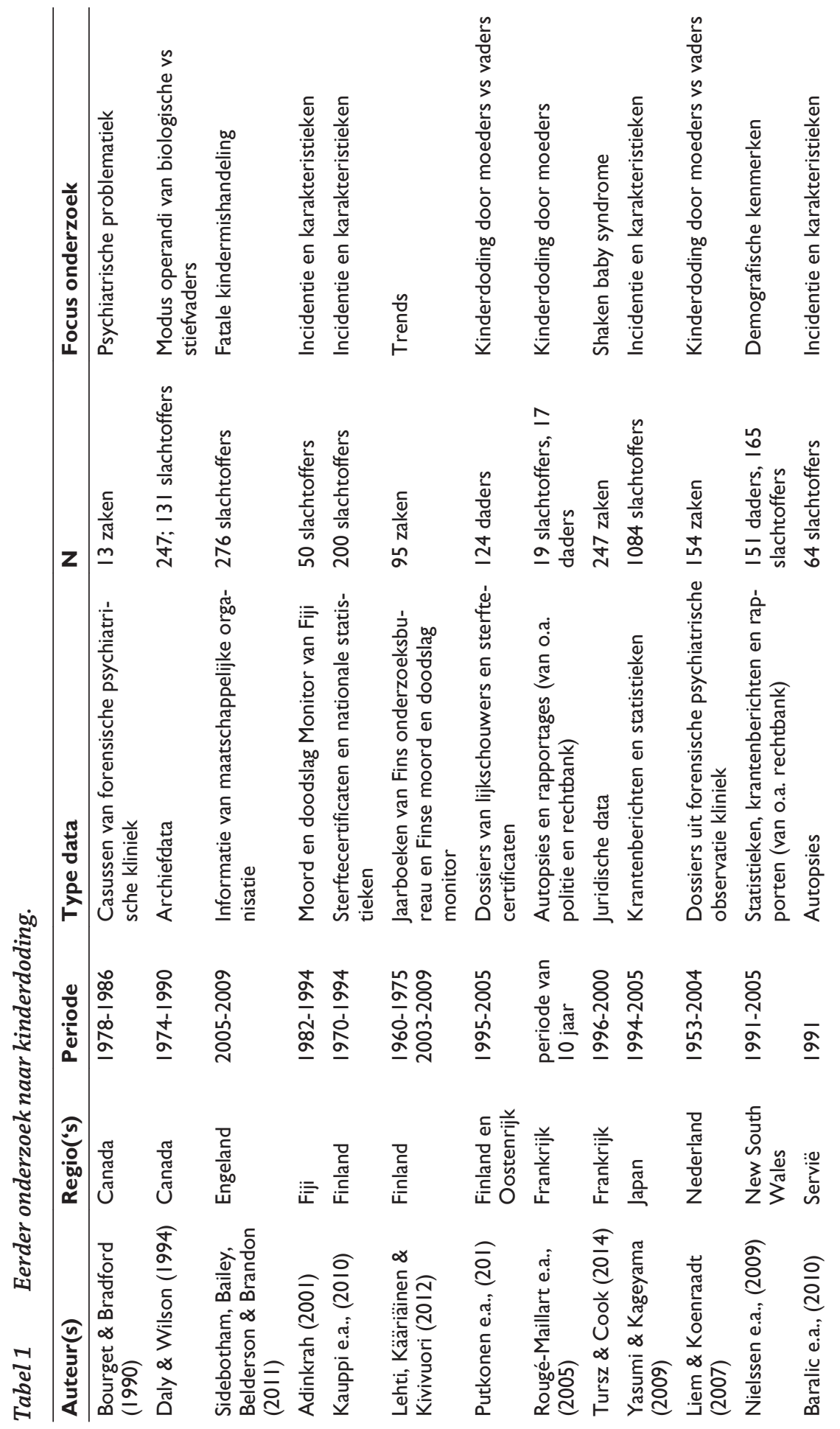




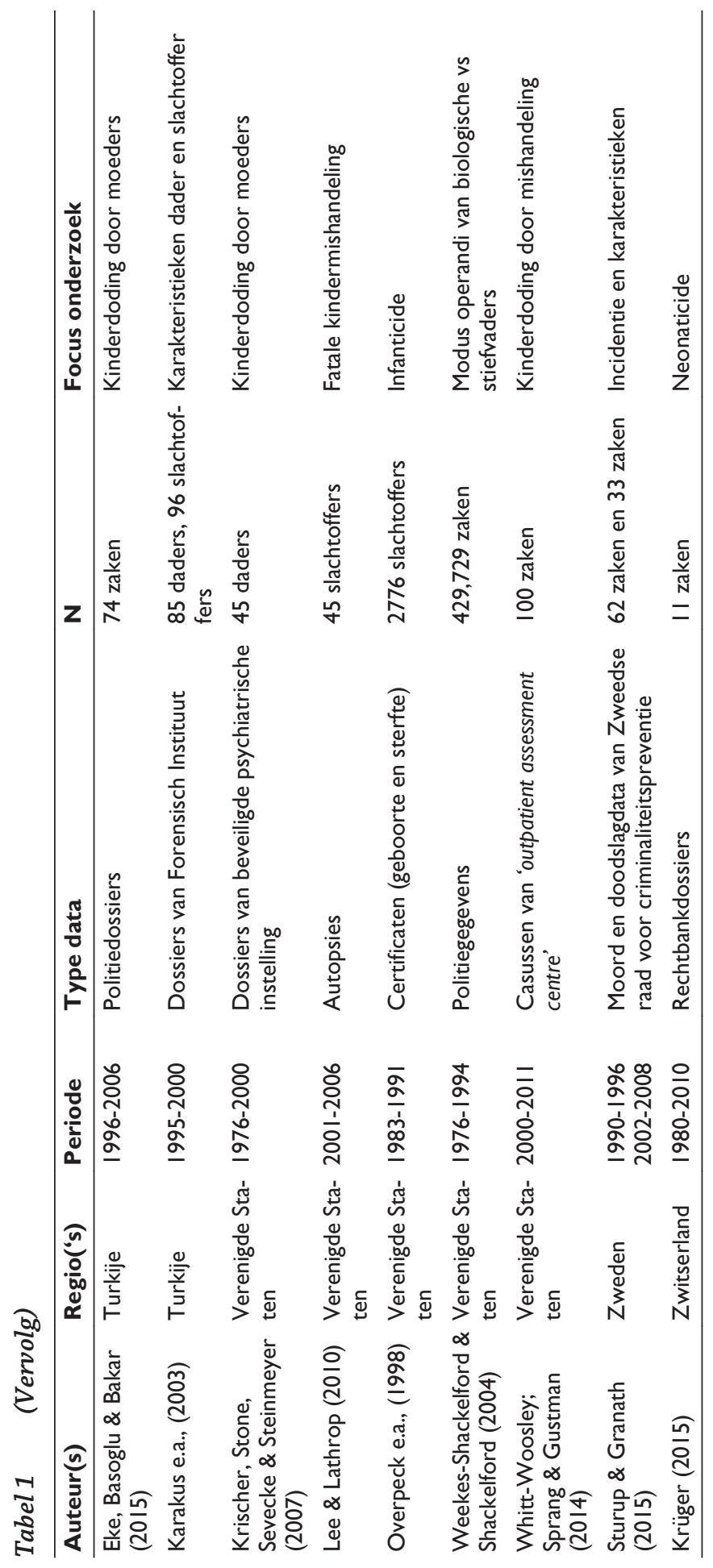




\subsection{Slachtofferkarakteristieken}

De grootste kans op slachtofferschap van kinderdoding geldt voor kinderen jonger dan 1 jaar en de kans op slachtofferschap neemt af naarmate kinderen ouder worden (Adinkrah 2001; Baralic e.a. 2010; Finkelhor \& Ormrod 2001; Kauppi, Kumpulainen, Karkola, Vanamo \& Merikanto 2010; Krüger 2015; Lee \& Lathrop 2010; Pritchard \& Sharples 2008; Yasumi \& Kageyama 2009), waarbij kinderen binnen 24 uur na de bevalling het grootste risico lopen (Bourget e.a. 2007). Een mogelijke verklaring hiervoor is een grotere kans op psychische stoornissen onder recent bevallen vrouwen, zoals postpartum depressie (Marks 1996; Pearlstein, Howard, Salisbury \& Zlotnick 2009; Resnick 1969; Spinelli 2014).

Jongens die slachtoffer worden van kinderdoding zijn vaak ouder dan meisjes die slachtoffer worden (Koenraadt \& Liem 2007). In niet-westerse landen is het aandeel meisjes onder slachtoffers van kinderdoding groter, zij worden vaker als ongewenst gezien (Chesler 2010; Cooney 2014; Rafferty 2013). Zo worden vrouwen in India in sommige gemeenschappen als tweederangs burgers gezien en genieten zonen de voorkeur. Aan dochters zijn hogere kosten verbonden; als zij trouwen, dienen de families immers een bruidsschat te betalen aan de familie van de bruidegom. Omdat dochters bij hun schoonfamilies gaan wonen, worden zij vaak gezien als tijdelijke familieleden die leiden tot een afname van het familiekapitaal (Praveen 2011).

\subsection{Daderkarakteristieken}

Het merendeel van de kinderdodingen wordt door één ouder gepleegd, variërend van $44 \%$ in Australië (Nielssen e.a. 2009), 62\% in de Verenigde Staten (US Departement of Justice, 2003), tot 70\% in Servië (Baralic e.a. 2010).

Veruit de meeste studies naar kinderdoding zijn uitgevoerd in westerse landen. Veel onderzoeken richtten zich op dodingen gepleegd door moeders. Uit diverse studies blijkt dat moeders die kinderen jonger dan 1 jaar doden, doorgaans jonger zijn dan moeders die kinderen ouder dan 1 jaar doden (Kauppi, Kumpulainen, Karkola, Vanamo \& Merikanto 2010; Krischer e.a. 2007; Resnick 1970). Veel studies naar kinderdoding door moeders richten zich op de rol van de psychische stoornis (Bourget e.a. 2007; Friedman e.a. 2005; Krischer e.a. 2007; Resnick 1970; Rougé-Maillart e.a. 2005). Vrouwelijke daders lijden vaker dan mannelijke daders aan psychische stoornissen (Liem \& Koenraadt 2008a; Putkonen e.a. 2010). Het voornaamste motief van waaruit vrouwen overgaan tot het plegen van kinderdoding is dan ook het psychotische motief (Bourget e.a. 2007; Krischer e.a. 2007; Lewis \& Bunce 2003; Liem \& Koenraadt 2008a), waarin zij de doding plegen onder invloed van wanen en hallucinaties. Daarnaast laat de literatuur zien dat neonaticide voornamelijk door moeders wordt gepleegd (Bourget \& Bradford 1990; Kauppi e.a. 2010). De voornaamste reden hiervoor is dat neonaticides vaak het gevolg zijn van ongewenste zwangerschappen, die door moeders verborgen worden gehouden. Door het doden van de pasgeborene kan de zwangerschap worden ontkend en kan de moeder weer door met haar leven, alsof er niets is gebeurd (Adinkrah 2001; Resnick 1970; Yasumi \& Kageyama 2009).

Studies naar kinderdoding door vaders wijzen uit dat zowel slachtoffers als daders ouder zijn dan bij kinderdoding door moeders (Kauppi e.a. 2010; Koenraadt \& 
Liem 2007; Putkonen e.a. 2010). Het onderliggende motief bij kinderdoding door de vader is niet zelden het doden uit wraak jegens de (ex-)partner of kinderdoding als gevolg van mishandelding (Lewis \& Bunce 2003; Liem \& Koenraadt 2008a). Daarnaast zijn mannen de voornaamste plegers van familicide, waarbij de doding vaak primair gericht is op de (ex-)partner en de kinderen daarna volgen (Liem \& Koenraadt 2008b; Liem, Levin, Holland \& Fox 2013; Johnson 2006; Wilson e.a. 1995).

Bepaalde daderkarakteristieken gaan op voor zowel moeders als vaders. Bij beiden zijn vaak diverse stimuli aanwezig die tot stress leiden en is het sociale vangnet vaak klein tot afwezig. Door gebrek aan een sociaal vangnet kunnen zij niet omgaan met de stressvolle situatie waarin zij verkeren en hierdoor neemt het risico op kinderdoding toe (Adinkrah 2001; Kauppi e.a. 2010; Nielssen e.a. 2009; Yasumi \& Kageyama 2009). Andere veelvoorkomende daderkarakteristieken betreffen werkloosheid (Anderson, Ambrosino, Valentine \& Lauderdale 1983; Yasumi \& Kageyama 2009), drank- en drugsgebruik (Bourget e.a. 2007; Finkelhor \& Ormrod 2001; Koenraadt \& Liem 2008) en psychische stressoren zoals een echtscheiding, lage sociaaleconomische status en een gebrek aan steun en hulp (Adinkrah 2001; Bourget e.a. 2007; Finkelhor \& Ormrod 2001).

\subsection{Copycat-effect}

De media rapporteren vaak uitgebreid over kinderdoding. Er is geopperd dat deze uitvoerige berichtgeving mensen op ideeën zou brengen om een soortgelijk delict te begaan (Helfgott 2015; Wijfjes 1997). In de literatuur wordt dit het copycateffect genoemd, gedefinieerd als imitatiegedrag naar aanleiding van informatie verspreid in de media (Bos, Van Es \& Vasterman 2011; Helfgott 2015). Een mogelijke verklaring van dit effect zou kunnen liggen in de grote rol die de media tegenwoordig in onze levens spelen en de grote rol van criminaliteit in de media. Geromantiseerde weergave van bepaalde vormen van geweld kan in extreme gevallen leiden tot een problematisch gebrek aan onderscheid tussen fantasie en realiteit (Helfgott 2015). Tegenwoordig komen de meeste mensen alleen in contact met geweld via de media; geweld wordt vaak niet persoonlijk meegemaakt. Overmatige, ongenuanceerde berichtgeving over extreem geweld kan theoretisch als een imitatiemechanisme werken en voor een copycat-effect zorgen (Helfgott 2015).

In de periode 1996-1997 was er in Nederland sprake van een zogenaamde 'mediahype' omtrent kinderdoding (Wijfjes 1997). In de periode van één jaar vonden twaalf kinderdodingsincidenten plaats, gepleegd door één of beide ouders. De jaren voorafgaand aan die periode kenden per jaar drie à vier kinderdodingen. De mediaberichtgeving was dusdanig excessief, dat er zelfs werd gesproken over een kinderdodingepidemie (Brants \& Koenraadt 2005). De psycholoog Wolters riep op om in die tijd niets over het onderwerp te publiceren. Er werd in de daaropvolgende periode een mediastilte van een halfjaar ingelast rondom kinderdoding. Brants en Koenraadt (2005), die de gevallen in 1996-1997 nader onderzochten, concludeerden dat het moeilijk was vast te stellen of het bij deze casussen daadwerkelijk om een copycat-effect ging. Wel achtten zij het mogelijk dat door onnodig gedetailleerde berichtgeving imitatiegedrag op gang kon worden gebracht. 
Hoewel tot op heden het copycat-effect met betrekking tot kinderdoding niet epidemiologisch is bestudeerd, is er veelvuldig onderzoek gedaan naar het copycateffect bij zelfdoding (Hong \& Lee 2015; Philips 1974; Stack 2003; Stack 2005). Zo bleek dat het aantal suïcides - vooral onder jongeren - in de Verenigde Staten en Engeland in augustus 1962, de maand waarin Marilyn Monroe een einde aan haar leven maakte, met $12 \%$ steeg (Philips 1974). Dit effect werd toegeschreven aan de buitensporige, romantiserende mediaberichtgeving omtrent haar dood (Bos e.a. 2011; Philips 1974). Een suïcidecluster als gevolg van uitgebreide media-aandacht staat bekend als het Werther-effect (Philips 1974), naar aanleiding van het boek uit 1774 van Goethe (Die Leiden des jungen Werthers), dat verondersteld werd een reeks suïcides te hebben veroorzaakt (Bos e.a. 2011). In eerder onderzoek wordt gesteld dat een suïcidecluster zich gedraagt als een epidemie (Haw e.a. 2013). Zo blijkt dat een copycat-effect bij suïcides het grootst is in de korte periode na het oorspronkelijke incident, variërend van drie dagen (Cheng e.a. 2011) tot vier weken (Ladwig e.a. 2012) en dat het risico op imitatiegedrag het grootst is wanneer het incident in de omgeving heeft plaatsgevonden (Zenere 2009). Tevens wijst de literatuur uit, dat het copycat-effect het sterkst is wanneer het geslacht en de te kiezen methode van de gepubliceerde zelfdoding overeenkomen (Niederkrotenthaler e.a. 2009; Fu \& Yip 2009). In dit onderzoek zullen we - naast het in kaart brengen van de aard en omvang van kinderdoding - tevens kijken of er mogelijk sprake is van een copycat-effect onder kinderdodingen in Nederland.

\section{Methoden}

\subsection{Procedure}

Dit onderzoek heeft als doel de aard en omvang van kinderdoding in Nederland voor de periode 2009-2014 inzichtelijk te maken. De jaarlijkse moordlijsten van het weekblad Elsevier vormen de basis van het epidemiologische deel van dit onderzoek. In deze moordlijsten wordt het totale overzicht van moord (art. 289, 291 WvS) en doodslag (art. 287, 288 en 290 WvS) in Nederland voor het desbetreffende jaar gegeven. Deze lijsten zijn gebaseerd op berichten van het Algemeen Nederlands Persbureau (ANP) en krantenberichten en geven informatie over slachtofferkarakteristieken, relatie tussen dader en slachtoffer en over waar, wanneer en hoe de moord is gepleegd (zie ook: Leistra \& Nieuwbeerta 2003). Daarnaast hebben we online moordlijsten geraadpleegd, waaruit een aantal extra zaken naar voren kwam dat is meegenomen in de analyses. ${ }^{2}$ De informatie uit Elseviers moordlijsten is als leidend beschouwd wanneer de informatie in deze bronnen onderling afweek. Voorts zijn er voor elke kinderdodingszaak aanvullende krantenberichten gezocht via de krantendatabank LexisNexis. Zoektermen die hiervoor zijn gebruikt, zijn de pleegdatum, de pleegplaats en trefwoorden 'dood' en 'kind' of 'baby'. Zowel ANP-berichten als berichten uit nationale en regionale kranten zijn geraadpleegd. De karakteristieken van de dader, het slacht- 
offer en de zaak zijn gecodeerd volgens een uniform gevalideerd Europees coderingssysteem (Ganpat e.a. 2011).

Aan de hand van beschrijvende statistieken worden achtereenvolgens de zaak-, slachtoffer- en daderkarakteristieken onderzocht. Wanneer gesproken wordt over primaire slachtoffers, wordt in het geval van een enkelvoudige kindermoord (met één slachtoffer) het slachtoffer bedoeld en in het geval van een meervoudige moord wordt het oudste kindslachtoffer bedoeld. We spreken in dit onderzoek gemakshalve over 'daders', waarbij we opmerken dat door de recente aard van de zaken niet alle verdachten ook daadwerkelijk zijn veroordeeld. De slachtofferratio per 100.000 inwoners is berekend op de bevolkingsomvang onder de 20 jaar in Nederland voor de desbetreffende jaren (Centraal Bureau voor de Statistiek 2015).

Tot slot wordt er met behulp van vergelijkend onderzoek onderzocht of er sprake is van een mogelijk copycat-fenomeen. Dit doen we door nader te kijken naar factoren uit eerder onderzoek naar suïcideclusters, zoals tijdsbestek (binnen een kwartaal), geografische nabijheid (binnen dezelfde regio), overeenkomstige daderen slachtofferkarakteristieken en tot slot overeenkomstige modus operandi en motief. Daarbij bekijken we allereerst het gemiddelde aantal kinderdodingen per jaar over een lange periode waar gepubliceerde gegevens beschikbaar zijn (1992-2008), aangevuld met gegevens vergaard in dit onderzoek (2009-2014), totaal de periode 1992-2014 omvattend. Als gedurende de onderzoeksperiode bepaalde periodes significant meer kinderdodingen kennen dan het gemiddelde, worden de casussen ervan uit die jaren nader onder de loep gehouden.

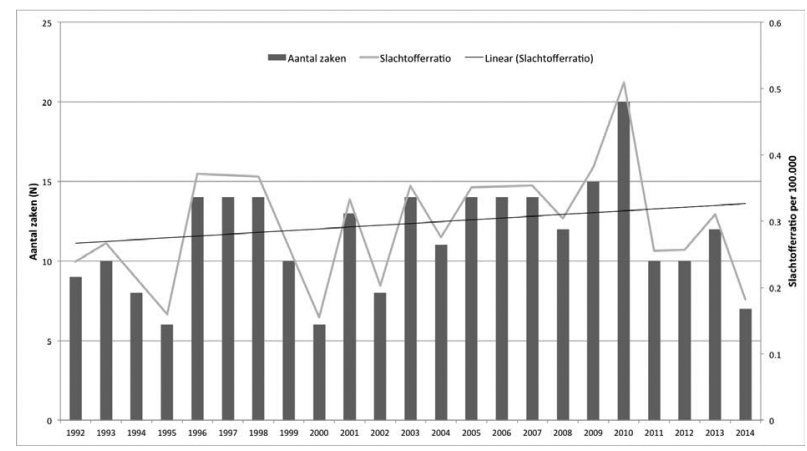

Figuur 1 Epidemiologie van kinderdoding in Nederland, 1992-2014.

\section{Resultaten}

\subsection{Zaakkarakteristieken}

In Nederland hebben in de periode 2009-2014 totaal 74 kinderdodingszaken plaatsgevonden. Dit zijn per jaar gemiddeld 14,8 zaken. Ter vergelijking: in de 
Tabel 2 Epidemiologie kinderdoding, Nederland 2009-2014 (N=74).

\begin{tabular}{llllllll}
\hline Zaakkarakteristieken & & & & & & \\
& $\mathbf{2 0 0 9}$ & $\mathbf{2 0 1 0}$ & $\mathbf{2 0 1 1}$ & $\mathbf{2 0 1 2}$ & $\mathbf{2 0 1 3}$ & $\mathbf{2 0 1 4}$ & Totaal \\
\hline Zaken & 15 & 20 & 10 & 10 & 12 & 7 & 74 \\
Slachtoffers & 17 & 22 & 12 & 12 & 16 & 7 & 86 \\
Daders & 18 & 25 & 13 & 12 & 13 & 9 & 90 \\
\hline
\end{tabular}

periode voorafgaand aan 2009, van 1992-2008, kende Nederland 191 kinderdodingszaken, gemiddeld 11,9 per jaar (zie figuur 1$)^{3}$ (Saan 2011).

Er zijn in de door ons onderzochte periode 2009-2014 in totaal 86 kinderen slachtoffer geworden en hierbij waren voor zover bekend 90 daders betrokken. Er zijn 30 zaken geclassificeerd als moord, 25 zaken zijn bestempeld als doodslag. Bij de overige zaken is het onduidelijk om wat voor type onnatuurlijke dood door toedoen van de dader het gaat. De plaats delict betreft in $88 \%$ een woning. Bijna negen op de tien kinderdodingszaken (89\%) werden opgelost. Tabel 2 laat zien dat 2010 het hoogste aantal zaken en de meeste slachtoffers kent. In 2014 daarentegen is het aantal zaken en slachtoffers het laagst.

Gedurende de onderzoeksperiode hebben zes familicides plaatsgevonden, waarbij naast kinderen ook (ex-)partners zijn gedood (zie tabel 3). In vijf van de zes gevallen beroofden de daders niet alleen kinderen en (ex-)partners van het leven, maar ook zichzelf.

Figuur 1 laat een sterke variatie zien in kinderdodingen door de tijd heen, variërend van 6 tot 20 zaken per jaar. De slachtofferratio per 100.000 inwoners onder de 20 jaar fluctueert van 0,24 slachtoffers per 100.000 in 1992 naar 0,18 slachtoffers per 100.000 in 2014. De trendlijn toont een lichte stijging aan in de slachtofferratio's gedurende de periode 1992-2014.

Tabel 3 Zaakkarakteristieken kinderdoding in Nederland, 2009-2014 (N=74).

\begin{tabular}{lll}
\hline & N & $\%$ \\
\hline Pleegplaats & 60 & 88 \\
Woning & 8 & 12 \\
Openbare plaats/werk/school/ & 8 & 100 \\
instelling & 74 & - \\
Totaal & 6 & \\
Onbekend & & 89 \\
Opgelost & 62 & 11
\end{tabular}


Tabel 3 (Vervolg)

\begin{tabular}{lll}
\hline & $\mathbf{N}$ & $\%$ \\
\hline Totaal & 74 & 100 \\
Onbekend & 4 & - \\
Familicide & & \\
2009 & 1 & 7 \\
2010 & 2 & 10 \\
2011 & 1 & 10 \\
2012 & 2 & 20 \\
\hline
\end{tabular}

\subsection{Slachtofferkarakteristieken}

Het merendeel van de slachtoffers is van het mannelijk geslacht, $58 \%$ jongens tegenover $42 \%$ meisjes. Het geslacht van drie slachtoffers is onbekend, in deze gevallen betreft het neonaticide. $86 \%$ van alle slachtoffers was jonger dan 13 jaar. Kinderdodingen zijn voor het overgrote deel intra-familiaal: $80 \%$ van alle slachtoffers betreft biologische kinderen van de dader en $12 \%$ van de slachtoffers is een stief-, pleeg- of adoptiekind van de dader of een ander familielid van de dader, zoals een oom. De gemiddelde leeftijd van de mannelijke slachtoffers is 5,9 jaar, tegenover 7,7 jaar onder de vrouwelijke slachtoffers. Dit verschil is echter niet significant $(F(2,83)=1,78, p>.05)$. Slachtofferratio's voor kinderen jonger dan 1 jaar liggen met 2,21 per 100.000 beduidend hoger dan slachtofferratio's voor kinderen onder de 20 jaar die in figuur 1 zijn weergegeven.

Tabel 4 Slachtofferkarakteristieken kinderdoding in Nederland, 2009-2014 $(N=86)$.

\begin{tabular}{lll}
\hline & $\mathbf{N}$ & $\%$ \\
\hline Geslacht & 48 & 58 \\
Man & 35 & 42 \\
Vrouw & 86 & 100 \\
Totaal & 3 & - \\
Onbekend & & \\
Leeftijd & 10 & 11 \\
$<$ dag & 13 & 15 \\
$<1$ jaar & 19 & 22 \\
I-4 jaar & 16 & 19 \\
$5-8$ jaar & 16 & 19 \\
$9-12$ jaar & 6 & 7 \\
13-17 jaar & 6 & 7 \\
=>18 jaar & &
\end{tabular}


Tabel $4 \quad$ (Vervolg)

$\mathbf{N} \%$

\section{Relatie tot dader}

Intra-familiaal

Kind

Stief/pleeg/adoptiekind, overige 10

familie

\begin{tabular}{lll} 
Extra-familiaal & 6 & 8 \\
Totaal & 86 & 100 \\
\hline
\end{tabular}

\subsection{Daderkarakteristieken}

De meeste daders van kinderdoding zijn mannen (56\%) en zijn ouder dan 40 jaar (32\%). Ongeveer een derde van alle kinderdodingen betreft pathologische kinderdodingen, met de altruïstische doding en de verlengde zelfdoding als subcategorieën. Bij tevens een derde van alle kinderdodingen is sprake van kinderdoding als ongeluk. Bij deze subcategorieën zijn er evenveel mannelijke als vrouwelijke daders betrokken (zie figuur 2). Gedurende de onderzoeksperiode is neonaticide zeven keer voorgekomen (9\%), zes kinderdodingen zijn vanuit het psychotisch motief gepleegd (8\%). Onder deze twee groepen zijn vrouwelijke daders oververtegenwoordigd (zie figuur 2). Kinderdodingen uit wraak jegens de partner, uit verlatingsangst of met een seksueel motief werden uitsluitend door mannen gepleegd (zie figuur 2).

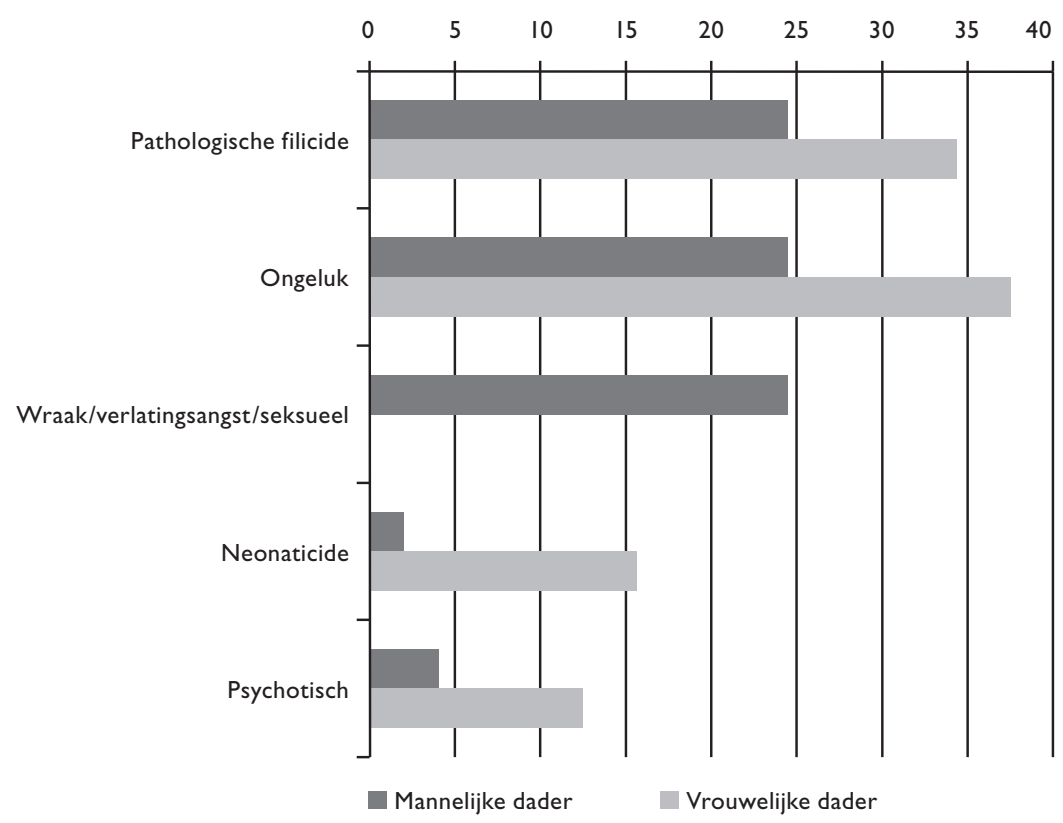

Figuur 2 Geslacht daders kinderdoding en motief in procenten, Nederland 2009-2014 $(N=86)$. 
Nederland kent in de onderzochte periode vijf extra-familiale kinderdodingen. In twee gevallen betrof het een seksueel motief, eenmaal was de kinderdoding een ongeluk (doodslag door een aanrijding) en twee keer heeft ruzie of pestgedrag tussen tieners tot de dood van het slachtoffer geleid.

Vuurwapens worden zelden gebruikt bij het doden van kinderen; de meeste kinderdodingen worden gepleegd met behulp van steekwapens, lichamelijk geweld of verstikking (zie figuur 3). Eén op de vijf daders heeft zich na de kinderdoding van het leven beroofd (23\%) en één op de tien deed een poging tot suïcide. Mannelijke daders plegen significant vaker zelfdoding $\left(\chi^{2}(\mathrm{df}=1)=6, p<.05\right)$, terwijl vrouwelijke daders vaker een poging doen. De gemiddelde leeftijd van het primaire slachtoffer is bij mannelijke daders hoger dan bij vrouwelijke daders, met 7 jaar tegenover 4,8 jaar. Dit verschil is echter niet significant $(F(2,86)=1,33, p>.05)$.

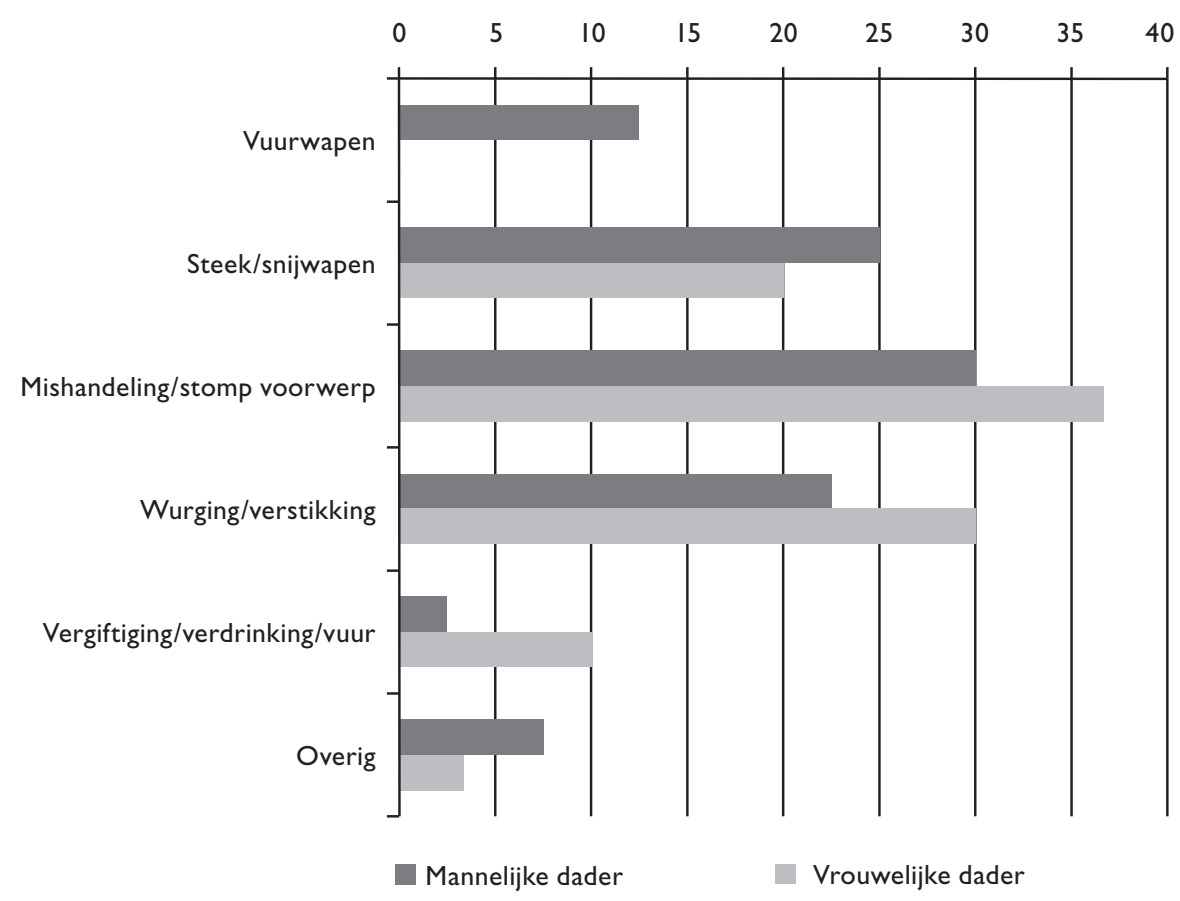

Figuur 3 Geslacht daders van kinderdoding en modus operandus in procenten, Nederland 2009-2014 (N=86).

\subsection{Copycat-effect}

Om na te gaan in hoeverre er onder kinderdodingen sprake is geweest van kopieergedrag, ofwel het zogenoemde copycat-effect, zullen we ons richten op een langere periode, namelijk die van 1992-2014. ${ }^{4}$ In totaal zijn er in deze periode 265 kinderdodingszaken geregistreerd, met een gemiddelde van 11,5 zaken per jaar. 
Tabel 5 Daderkarakteristieken kinderdoding in Nederland, 2009-2014 $(N=86)$.

\begin{tabular}{lll}
\hline & N & $\%$ \\
\hline Geslacht & 48 & 56 \\
Man & 38 & 44 \\
Vrouw & 90 & 100 \\
Totaal & 4 & - \\
Onbekend & & \\
Leeftijd & 6 & 7 \\
|3-17 & 17 & 20 \\
|8-24 & 14 & 16 \\
$25-30$ & 21 & 25 \\
$31-40$ & 27 & 32 \\
$>4 \mid$ & 100 & 100 \\
Totaal & 5 & - \\
Onbekend & & \\
\hline
\end{tabular}

Voor 2009-2014 wordt gekeken in welke periodes er meer kinderdodingszaken plaatsvonden dan verwacht op basis van het gemiddelde. In de jaren 2009 (15 zaken) en 2010 (20 zaken) vonden significant meer zaken plaats dan het gemiddelde $(t=-4,9 ; p<0,01)$ en $(t=-12 ; p<0,01)$. We zullen de zaken uit deze jaren nader onder de loep nemen. Allereerst is gekeken naar de periode waarin kinderdodingen plaatsvonden. Indien de pleegdata dicht bij elkaar liggen, vergelijken we de zaken op basis van geografische spreiding, dader- en slachtofferkarakteristieken en modus operandus.

Zo zijn er in de twee bestudeerde jaren twee temporale clusters te onderscheiden, waarin binnen één kwartaal verhoudingsgewijs een groot aantal kinderdodingen plaatsvindt. Zo vinden in 2009 de meeste kinderdodingen (7 zaken) plaats in mei en juni. Twee van de zeven zaken vinden plaats in dezelfde politieregio (Den Haag), de overige zeven zaken vinden elders in het land plaats. Vijf daders zijn man; in twee neonaticide-zaken blijft de dader onbekend. In deze periode komt kinderdoding uit wraak of als ongeluk beide één keer voor. De overige drie kinderdodingen betreffen zogenoemde pathologische dodingen. Bij twee van deze drie zaken is het moordwapen een steekwapen. Nadere bestudering laat zien, dat deze twee moorden echter veel verschillen vertonen. Zo betreft de ene zaak een familicide waarbij de dader zichzelf tevens van het leven heeft beroofd, terwijl de andere zaak één dodelijk slachtoffer telt, het stiefkind van de dader.

In 2010 vinden veruit de meeste kinderdodingen (9 zaken) plaats in de periode juli tot en met september. Drie van de negen zaken komen voor in de politieregio Oost-Nederland. Eén zaak betreft een neonaticide door een onbekende dader; beide andere zaken betreffen dodelijke mishandeling van een jong kind door hun vader. Door het impulsieve karakter van deze dodingen en het feit dat de doding resulteert als onbedoeld gevolg van mishandeling, is er geen aanwijzing voor imi- 
tatiegedrag. Twee andere zaken binnen dit cluster vinden plaats in de politieregio Den Haag. Deze zaken verschillen echter aanzienlijk van elkaar. Eén zaak betreft een 47-jarige moeder die haar zoon met een steekwapen doodt; de andere zaak betreft een 37-jarige man die zijn 3-jarige dochter doodt door brandstichting. Bij beide daders is er sprake van een vergaande invloed van een psychische stoornis. Dit cluster kent voorts twee kinderdodingen in de politieregio Limburg. Eén zaak draait om een 41-jarige moeder die haar pasgeboren kind doodt; de andere zaak kent een 42-jarige vader die zijn 11-jarige zoontje door verstikking om het leven brengt.

Hoewel er in deze twee temporale clusters overeenkomsten te vinden zijn in bepaalde aspecten, zoals geografische spreiding of modus operandus, bestaan grote verschillen tussen andere belangrijke aspecten zoals de leeftijd van het slachtoffer, het geslacht van de dader of het motief.

\section{Discussie en conclusie}

Gedurende de periode 2009-2014 hebben 74 kinderdodingszaken plaatsgevonden in Nederland, hetgeen neerkomt op ongeveer twaalf zaken per jaar. Met betrekking tot zaak-, slachtoffer- en daderkarakteristieken sluiten de bevindingen van dit onderzoek aan op eerdere nationale en internationale studies naar kinderdoding. Zo zijn verreweg de meeste kinderdodingen intra-familiaal en worden ze in woningen gepleegd (Baralic e.a. 2010; Nielssen e.a. 2009; US Department of Justice 2003). Tevens vonden we dat jonge kinderen het grootste risico lopen slachtoffer te worden, waarbij mannelijke daders oudere slachtoffers maken dan vrouwelijke daders. Dit is te verklaren door de verschillen in typen kinderdoding: waar vrouwen zijn oververtegenwoordigd onder plegers van neonaticide en zeer jonge kinderen, zijn mannen de voornaamste daders van kinderdoding uit wraak, bijvoorbeeld in de context van een echtscheiding. In dergelijke gevallen hebben kinderen doorgaans een hogere leeftijd.

Eveneens overeenkomstig de internationale literatuur vonden we dat de meest prevalente modus operandus steekwapens, lichamelijk geweld en verstikking betrof (zie ook: Koenraadt \& Liem 2007; Putkonen, Amon, Eronen, Klier, Almiron, Yourstone-Cederwall e.a. 2010). Vaders gebruiken vaker schietwapens en steekwapens, terwijl moeders minder gewelddadige methoden gebruiken, zoals vuur, vergiftiging en verdrinking. Dat de mannelijke daders in dit onderzoek vaker overgaan tot zelfdoding na hun kind(eren) te hebben gedood, vindt tevens aansluiting bij eerder onderzoek (Bourget e.a. 2007; Putkonen e.a. 2010). Dit kan mogelijk verklaard worden door het feit dat wanneer mannen suïcide plegen, ze dit met gewelddadigere methoden doen dan vrouwen (Kerkhof 2010). Mannen lopen daardoor verhoudingsgewijs meer kans te overlijden dan vrouwen met een wellicht vergelijkbare suïcidale intentie.

Dit onderzoek had tevens als doel te kijken in hoeverre er sprake is van een imitatie-effect onder kinderdodingen in Nederland. In de twee temporale clusters die zijn onderzocht, zijn allereerst de zaken die in dezelfde politieregio hebben plaats- 
gevonden met elkaar vergeleken. Per politieregio is gekeken naar overeenkomsten in dader- en slachtofferkarakteristieken, modus operandus en motief. Zo werden bij enkele zaken overeenkomsten gevonden in bijvoorbeeld de geografische spreiding of de modus operandus. Nadere bestudering liet zien dat zaken in een andere tijdsspanne waren gepleegd of geen gelijkenis vertoonden in dader- en slachtofferkarakteristieken. De meeste overeenkomsten zijn gevonden in twee zaken in Oost-Nederland, waar twee vaders hun jonge kind om het leven brachten door mishandeling. Bij deze zaken kan echter niet met zekerheid worden gesproken van een imitatie-effect, aangezien de dood bij beide zaken een onbedoeld gevolg is geweest van mishandeling in plaats van een vooropgezet plan om het jeugdige slachtoffer van het leven te beroven. De gevonden overeenkomsten tussen zaken zijn tot dusver onvoldoende om van een copycat-effect te spreken bij kinderdodingen in Nederland voor de periode 2009-2014.

\subsection{Implicaties voor preventie}

De factoren die leiden tot kinderdoding zijn multicausaal (zie ook: Liem, Koenraadt \& Hengeveld 2009), variërend van echtscheidingsproblematiek, financiële problematiek, psychische problematiek tot suïcidale problematiek. Bij het ontwikkelen van mogelijkheden tot preventie van kinderdoding dienen risicotaxaties van zowel geweld naar kinderen gericht, als geweld naar zichzelf gericht, hand in hand te gaan. Kinderdoding is bij uitstek een delict dat gepaard gaat met een hoge mate van psychopathologie bij de dader. Bij achteruitgang van de psychische gezondheid door depressie en/of psychose, al dan niet gepaard gaande met echtscheiding of dreiging daartoe, dienen hulpverleners een volledige beoordeling van relaties met kinderen, inclusief (ex-)partners, te maken. Communicatie tussen verschillende (GGZ-) instellingen, kinderbescherming en andere betrokken partijen is hierbij noodzakelijk.

Hoewel deze studie niet genoeg ondersteuning vond voor een zogenoemd 'copycat-effect' bij kinderdodingen, valt dit door de relatief kleine aantallen op microniveau tevens niet uit te sluiten. Vanuit de suïcideliteratuur weten we, dat diegenen die overgaan tot een imitatiezelfdoding, veel risicofactoren voor zelfdoding bezitten, zoals middelmisbruik, werkloosheid en eerdere suïcidaliteit (Haw e.a. 2013). Om het risico op imitatiezelfdoding te minimaliseren, hanteert de journalistiek in Nederland doorgaans een aantal richtlijnen (zie ook: Ivonne van de Ven Stichting 2007). Totdat een copycat-effect onder kinderdoding kan worden uitgesloten, verdient het aanbeveling dat media zich houden aan dezelfde richtlijnen zoals die gelden voor zelfdoding: de moord niet afschilderen als een redelijke oplossing voor problemen, niet op nauwkeurige wijze over de methode berichten en vermijden om romantiserend of verheerlijkend over de moord te spreken of de moord (al dan niet met beeldmateriaal) een prominent platform te bieden.

\subsection{Vervolgonderzoek}

Tot op heden ontbrak het aan een overzicht omtrent de aard en omvang van kinderdoding in Nederland in recente jaren. Met dit onderzoek hebben we de bestaande lacune trachten op te vullen. Dit onderzoek kent echter enkele beperkingen. Ten eerste is voor de informatievoorziening louter gebruikgemaakt van 
mediaberichtgeving, waardoor niet alle zaakinformatie beschikbaar was. Desondanks is de mediaberichtgeving rondom kinderdoding omvangrijk en zijn veel details beschikbaar over diverse kinderdodingszaken. Daarnaast hebben diverse eerdere onderzoeken laten zien dat op basis van mediaberichtgeving als primaire informatiebron een goede inschatting gemaakt kan worden van zeldzame vormen van doding, waaronder kinderdoding (Liem \& Koenraadt 2007; Malphurs \& Cohen 2002; Roma e.a. 2012; Peelo, Francis, Soothill, Pearson \& Ackerley 2004). Vervolgonderzoek heeft als doel deze bron aan te vullen met door de diverse politiekorpsen gevalideerde informatie. Ten derde kan er sprake zijn van onderschatting van het aantal slachtoffers. De dood van een kind kan ten onrechte worden bestempeld als een wiegendood (Sudden Infant Death Syndrome) of een ongeluk (Yasumi \& Kageyama 2009; Overpeck e.a. 1998). Daarnaast is het mogelijk dat vrouwen van wie niemand weet dat ze zwanger zijn, ongemerkt hun baby doden en verbergen zonder dat iemand daar ooit achter komt (Adinkrah 2001; Resnick 1970; Yasumi \& Kageyama 2009).

Uit onderzoek naar suïcideclusters is bekend dat een imitatie-effect sterker aanwezig wanneer er uitgebreide, gedetailleerde berichtgeving naar een specifieke zelfdoding uitgaat, en wanneer in geromantiseerde termen over de zelfdoding wordt bericht (Haw e.a. 2013). Om meer zekerheid te krijgen over de aard van een mogelijk copycat-effect bij kinderdoding, zouden vervolgstudies gebruik kunnen maken van contentanalyse van mediaberichtgeving. Daarnaast zou vervolgonderzoek gebruik kunnen maken van daderinterviews of - in het geval van het overlijden van de dader - de zogenoemde psychologische autopsie-methode (Cavanagh, Carson, Sharpe \& Lawrie 2003), waarin nabestaanden wordt gevraagd naar de omstandigheden die leidden tot de kinderdoding. Door dergelijke informatie kunnen eventuele individuele imitatie-effecten, die onderbelicht blijven bij een statistische benadering, worden bestudeerd. Op deze manier zou tevens een beter beeld kunnen worden geschetst van de aard en hoeveelheid van nieuwsberichten en de mogelijke relatie tot imitatiegedrag.

\section{Literatuur}

Adinkrah, M. (2001) When parents kill: An analysis of filicides in Fiji. International Journal of Offender Therapy and Comparative Criminology, 45(2), 144-158.

Anderson, R., R. Ambrosino, D. Valentine \& M. Lauderdale (1983) Child deaths attributed to abuse and neglect: An empirical study. Children and Youth Services Review, 5(1), 75-89.

Baralic, I., S. Savic, D. Alempijevic, D. Jecmenica, G. Sbutega-Milosevic \& M. Obradovic (2010) Child homicide on the territory of Belgrade. Child Abuse \& Neglect, 34(12), 935-842.

Bos, J.G.H., A.M.D. van Es \& P. Vasterman (2011) Copycat. Den Haag: COT Instituut voor Veiligheids- en Crisismanagement.

Bourget, D. \& J. Bradford (1990) Homicidal parents. Canadian Journal of Psychiatry, 35(3), 233-238.

Bourget, D., J. Grace \& L. Whitehurst (2007) A review of maternal and paternal filicide. Journal of the American Academy of Psychiatry and the Law Online, 35(1), 74-82. 
Brants, C.H. \& F. Koenraadt (1998) Criminaliteit en media-hype. Een terugblik op de publieke beeldvorming rond kindermoord. Delikt en Delinkwent, 28(6), 542-564.

Cavanagh, J.T., A.J. Carson, M. Sharpe \& S.M. Lawrie (2003) Psychological autopsy studies of suicide: a systematic review. Psychological medicine, 33(03), 395-405.

Centraal Bureau voor de Statistiek (2015) Bevolking; geslacht, leeftijd en burgerlijke staat, 1 januari. Verkregen van: http://statline.cbs.nl/Statweb/publication/?DM=SLNL\&PA= 7461BEV\&D1=0\&D2=0\&D3 =1-27,101-105,121-123,131\&D4=42-65\&HDR $=$ $\mathrm{T}, \mathrm{G} 3, \mathrm{G} 1 \& \mathrm{STB}=\mathrm{G} 2 \& \mathrm{VW}=\mathrm{T}$.

Cheng, Q., F. Chen \& P.S. Yip (2011) The foxconn suicides and their media prominence: is the Werther effect applicable in China?. BMC Public Health, 11, 841.

Chesler, P. (2010) Worldwide trends in honor killings. Middle East Quarterly, 1, 3-11.

Cooney, M. (2014) Death by family: Honor violence as punishment. Punishment \& Society, 16(4), 406-427.

Daly, M. \& M.I. Wilson (1994) Some differential attributes of lethal assaults on small children by stepfathers versus genetic fathers. Ethology and Sociobiology, 15(4), 207-217.

Eke, S.M., S. Basoglu, B. Bakar \& G. Oral (2015) Maternal filicide in Turkey. Journal of Forensic Sciences, 60(1), 143-151.

Ellonen, N., J. Kääriäinen, M. Lehti \& M. Aaltonen (2015) Comparing trends in infanticides in 28 countries, 1960-2009. Journal of Scandinavian Studies in Criminology and Crime Prevention, doi: 10.1080/14043858.2015.1038905.

Finkelhor, D. \& R. Ormrod (2001) Homicides of children and youth. Juvenile Justice Bulletin, 12, 1-12.

Fox, J.A. \& M.W. Zawitz (2003) Homicide trends in the United States: 2000 Update. Verkregen op 6 juni 2015 van www.ojp.usdoj.gov/bjs/homicide/homtrnd.htm.

Friedman, S., S. Horwitz \& P. Resnick (2005) Child murder by mothers: A critical analysis of the current state of knowledge and a research agenda. The American Journal of Psychiatry, 162, 1578-1587.

Fu, K.W. \& P.S. Yip (2009) Estimating the risk for suicide following the suicide deaths of 3 Asian entertainment celebrities: a meta-analytic approach. The Journal of clinical psychiatry, 70(6), 1-478.

Ganpat, S.M., S. Granath, J. Kivivuori, M. Lehti, M.C.A. Liem \& P. Nieuwbeerta (2011) Homicide in Finland, the Netherlands and Sweden: A first study on the European homicide monitor data. Stockholm: Brå.

Haw, C., K. Hawton, C. Niedzwiedz \& S. Platt (2013) Suicide clusters: a review of risk factors and mechanisms. Suicide and life-threatening behavior, 43(1), 97-108.

Helfgott, J.B. (2015) Criminal behavior and the copycat effect: Literature review and theoretical framework for empirical investigation. Aggression and violent behavior, 22, 46-64.

Hong, S.C. \& J. Lee (2015) People on the verge of death: evidence from impacts of celebrity suicides. Applied Economics, 47(7), 710-724.

Ivonne Van de Ven Stichting (2007) Sü̈cide in de media. Een richtlijn. Arnhem: Ivonne van de Ven Stichting.

Johnson, C.H. (2006) Familicide and family law: a study of filicide-suicide following separation. Family Court Review, 44(3), 448-463.

Karakus, M., H. Ince, N. Ince, N. Arican \& S. Sozen (2003) Filicide cases in Turkey, 1995-2000. Croatian Medical Journal, 44(5), 592-595.

Kauppi, A., K. Kumpulainen, K. Karkola, T. Vanamo \& J. Merikanto (2010) Maternal and paternal filicides: A retrospective review of filicides in Finland. Journal of The American Academy of Psychiatry and the Law Online, 38(2), 229-238. 
Kerkhof, A. (2010) Epidemiologie van suïcidaal gedrag. In: Suïcidepreventie in de praktijk (p. 23-38). Houten: Bohn Stafleu van Loghum.

Koenraadt, F. (2003) Doding van een pasgeborene - een verborgen delict. In: T.I. Oei \& M.S. Groenhuijsen (red.), Actuele ontwikkelingen in de forensische psychiatrie (p. 201-206). Deventer: Kluwer.

Koenraadt, F. \& M. Liem (2008) Kinderen als fataal slachtoffer van eigen ouders. In: F. Koenraadt \& M. Liem (eds.), Het kind als slachtoffer. Patronen en preventie van (fataal) geweld in gezinsverband (p. 11-30). Amsterdam: Rozenberg publishers.

Krischer, M., M. Stone, K. Sevecke \& E. Steinmeyer (2007) Motives for maternal filicide: Results from a study with female forensic patients. International Journal of Law and Psychiatry, 30, 191-200.

Krüger, P. (2015) Prevalence and phenomenology of neonaticide in Switzerland 1980-2010: a retrospective study. Violence and Victims, 30(2), 194-207.

Ladwig, K.-H., S. Kunrath, K. Lukaschek, J. Baumert (2012) The railway suicide death of a famous German football player: impact on the subsequent frequency of railway suicide acts in Germany. Journal of Affective Disorders, 136, 194-198.

Lee, C. \& S. Lathrop (2010) Child abuse-related homicides in New Mexico: A 6-year retrospective review. Journal of Forensic Sciences, 55(1), 100-103.

Lehti, M., J. Kääriäinen \& J. Kivivuori (2012) The Declining Number of Child Homicides in Finland, 1960-2009. Homicide Studies, 16(1), 3-22.

Leistra, G. \& P. Nieuwbeerta (2003) Moord en doodslag in Nederland. Amsterdam: Prometheus.

Lewis, C. \& B. Scott (2003) Filicidal mothers and the impact of psychosis on maternal filicide. The Journal of the American Academy of Psychiatry and the Law, 31(4), 459-470.

Liem, M., M. Hengeveld \& F. Koenraadt (2009) Kinderdoding gevolgd door een ernstige poging tot zelfdoding. Tijdschrift voor Criminologie, 51(3), 262-276.

Liem, M. \& F. Koenraadt (2007) Homicide-suicide in the Netherlands: A study of newspaper reports, 1992-2005. The Journal of Forensic Psychiatry \& Psychology, 18(4), 482-493.

Liem, M. \& F. Koenraadt (2008a) Filicide: A comparative study of maternal versus paternal child homicide. Criminal Behaviour and Mental Health, 18, 166-176.

Liem, M. \& F. Koenraadt (2008b) Familicide: a comparison with spousal and child homicide by mentally disordered perpetrators. Criminal Behaviour and Mental Health, 18(5), 306-318.

Liem, M., J. Levin, C. Holland \& J.A. Fox (2013) The nature and prevalence of familicide in the United States, 2000-2009. Journal of Family Violence, 28(4), 351-358.

Liem, M., R. de Vet \& F. Koenraadt (2010) Filicide followed by parasuicide: A comparison of suicidal and non-suicidal child homicide. Child Abuse \& Neglect, 34, 558-562.

Malphurs, J.E. \& D. Cohen (2002) A newspaper surveillance study of homicide-suicide in the United States. The American Journal of Forensic Medicine and Pathology, 23(2), 142-148.

Marks, M.N. (1996) Characteristics and causes of infanticide in Britain. International Review of Psychiatry, 8(1), 99-106.

Niederkrotenthaler, T., B. Till, N.D. Kapusta, M. Voracek, K. Dervic, G. Sonneck (2009). Copycat effects after media reports on suicide: a population-based ecological study. Social Science \& Medicine 69, 1085-1090.

Nielssen, O., M. Large, B. Westmore \& S. Lackersteen (2009) Child homicide in New South Wales from 1991 to 2005. The Medical Journal of Australia, 190(1), 7-11. 
Overpeck, M., R. Brenner, A. Trumble, L. Trifiletti \& H. Berendes (1998) Risk factors for infant homicide in the United States. The New England Journal of Medicine, 339(17), 1211-1216.

Pearlstein, T., M. Howard, A. Salisbury \& C. Zlotnick (2009) Postpartum depression. American Journal of Obstetrics and Gynecology, 200(4), 357-364.

Peelo, M., B. Francis, K. Soothill, J. Pearson \& E. Ackerley (2004) Newspaper reporting and the public construction of homicide. British Journal of Criminology, 44(2), 256-275.

Philips, D. (1974) The Influence of suggestion on suicide: Substantive and theoretical implications of the Werther effect. American Sociological Review, 39, 340-354.

Porter, T. \& H. Gavin (2010) Infanticide and neonaticide: A review of 40 years of research literature on incidence and causes. Trauma, Violence \& Abuse, 11(3), 99-112.

Praveen, S. (2011) Female infanticide. Journal of Indian Academy of Forensic Medicine, 33(4), 364-367.

Pritchard, C. \& A. Sharples (2008) 'Violent' deaths of children in England and Wales and the major developed countries 1974-2002: Possible evidence of improving child protection?. Child Abuse Review, 17, 297-312.

Putkonen, H., S. Amon, M. Eronen, C.M. Klier, M.P. Almiron, J. Yourstone-Cederwall e.a. (2010). A comprehensive register-based study of child murder in two European countries. Journal of Forensic Psychiatry \& Psychology, 21(5), 637-648.

Rafferty, Y. (2013) International dimensions of discrimination and violence against girls: A human rights perspective. Journal of International Women's Studies, 14(1), 1-23.

Resnick, P.J. (1969) Child murder by parents: a psychiatric review of filicide. American Journal of Psychiatry, 126(3), 325-334.

Resnick, P. (1970) Murder of the newborn: A psychiatric review of neonaticide. The American Journal of Psychiatry, 126(10), 1414-1420.

Roma, P., A. Spacca, M. Pompili, D. Lester, R. Tatarelli, P. Girardi \& S. Ferracuti (2012) The epidemiology of homicide-suicide in Italy: A newspaper study from 1985 to 2008. Forensic Science International, 214(1), 1-5.

Rougé-Maillart, C., N. Jousset, A. Gaudin, B. Bouju \& M. Penneau (2005). Women who kill their children. The American Journal of Forensic Medicine and Pathology, 26(4), 320-326.

Saan, M. (2011) Kinderdoding. De aard en incidentie in Nederland in de periode 1992-2009. (ongepubliceerde masterscriptie). Leiden: Universiteit Leiden.

Sidebotham, P., S. Bailey, P. Belderson \& M. Brandon (2011) Fatal child maltreatment in England, 2005-2009. Child Abuse \& Neglect, 35(4), 299-306.

Spinelli, M.G. (2004) Maternal infanticide associated with mental illness: Prevention and the promise of saved lives. American Journal of Psychiatry, 161 (9), 1548-1557.

Spinelli, M.G. (2014) A systematic investigation of 16 cases of neonaticide. American Journal of Psychiatry, 158, 811-813.

Stack, S. (2003) Media coverage as a risk factor in suicide. Journal of Epidemiology and Community Health, 57(4), 238-240.

Stack, S. (2005) Suicide in the media: A quantitative review of studies based on nonfictional stories. Suicide and Life-Threatening Behavior, 35(2), 121-133.

Stern, E. S. (1948) The Medea complex: The mother's homicidal wishes to her child. The British Journal of Psychiatry, 94(395), 321-331.

Sturup, J. \& S. Granath (2014) Child homicides in Sweden: a descriptive study comparing the 1990s and the 2000s. Homicide Studies, 19(2), 175-187.

Tursz, A. \& J.M. Cook (2014) Epidemiological data on shaken baby syndrome in France using judicial sources. Pediatric Radiology, 44(4), 641-646.

U.S. Department of Justice (2003) Homicide trends in the United States. Verkregen van: www.bjs.gov/content/pub/pdf/htus00.pdf. Washington D.C. 
Van Os, R., P. Nieuwbeerta \& S.M. Ganpat (2010) Moord en Doodslag in Nederland. In: E. Muller (red.), Criminaliteit. Deventer: Kluwer.

Weekes-Shackelford, V.A. \& T.K. Shackelford (2004) Methods of filicide: Stepparents and genetic parents kill differently. Violence and Victims, 19(1), 75-81.

Whitt-Woosley, A., G. Sprang \& B.D. Gustman (2014) Lives at risk: Uncovering factors associated with fatal child maltreatment. Children and Youth Services Review, 47, 307-313.

Wijfjes, H. (1997) Pleidooi voor mediastilte eenzijdig. De Journalist, 30-31.

Wilson, M., M. Daly \& A. Daniele (1995) Familicide: The killing of spouse and children. Aggressive Behaviour, 21, 275-291.

Yasumi, K. \& J. Kageyama (2009) Filicide and fatal abuse in Japan, 1994-2005: Temporal trends and regional distribution. Journal of Forensic and Legal Medicine, 16, 70-75.

Yip, P.S., K.W. Fu, K.C. Yang, B.Y. Ip, C.L. Chan, E.Y. Chen, D.T. Lee, F.Y. Law \& K. Hawton (2006) The effects of a celebrity suicide on suicide rates in Hong Kong. Journal of Affective Disorders, 93, 245-252.

Zenere, F.J. (2009) Suicide clusters and contagion. Principal Leadership, 10, 12-16. 